\title{
Pengaruh Rasio Laju Alir Gas Nitrogen-Hidrogen serta Gas Pressure pada RF Plasma Nitriding terhadap Surface Hardness Spesimen SUS304
}

\author{
Tjuk Oerbandono \\ Jurusan Teknik Mesin Universitas Brawijaya \\ JI. MT. Haryono 167 Malang, +62-0341-587710 \\ E-mail: toerbandono@ub.ac.id
}

\begin{abstract}
RF Plasma nitriding was done on the specimen SUS304. The research had aim to obtain a high surface hardness value. The conducted research was experimental research and consisted of three experimental models. Each experimental model used varying parameters and constant parameters. Surface hardness test was conducted on each result of the experimental model. Surface hardness value of specimen was as a result of variations in the specified parameters in each of the experimental model. Surface hardness or micro hardness test method in the research was the Micro Vickers Hardness. For the first experimental model, the variable parameter was time of plasma nitriding, ie, 1 hour, 2 hours, 4 hours and 8 hours. The constant parameters were RF-Power Voltage $=250$ Volts, $D C$-Bias Voltage $=500$ Volts, $N_{2}=100(\mathrm{ml} / \mathrm{min})$, $\mathrm{H}_{2}=20(\mathrm{ml} / \mathrm{min})$, Gas pressure $(P)=70 \mathrm{~Pa}$ and Heater Temperature $(T)=420^{\circ} \mathrm{C}$. The second experimental model contained three variable parameters of nitrogen gas pressure ie, $50 \mathrm{~Pa}, 60 \mathrm{~Pa}$ and $70 \mathrm{~Pa}$. The constant parameters of the second experimental model were time of plasma nitriding $(t)=8$ Hours, RF-Power Voltage $=250$ Volts, Heater Temperature $(T)=420^{\circ} \mathrm{C}, \mathrm{N}_{2}=140(\mathrm{ml} / \mathrm{min}), H_{2}=$ $20(\mathrm{ml} / \mathrm{min})$. The first and second experimental models had the same configuration. The third experimental model used three variations of the flow rate of nitrogen gas, ie, $140(\mathrm{ml} / \mathrm{min}), 160(\mathrm{ml} / \mathrm{min}), 180(\mathrm{ml} / \mathrm{min})$. The constant parameters were time of plasma nitriding $(t)=4$ hours, $R F$-Voltage $=250$ volts, The Heater temperature $(T)=420^{\circ} \mathrm{C} ; \mathrm{H}_{2}=20(\mathrm{ml} / \mathrm{min}), D C$-Bias Voltage $=500$ Volts, the gas pressure $(P)=60 \mathrm{~Pa}$. The configuration of third experimental model was different with the configurations in first and second experimental models. Values of surface hardness on the first experimental model for plasma nitriding time of 1 hour, 2 hours, 4 hours and 8 hours were; 379 HV, 348 HV, 474 HV and 387 HV. The surface hardness values of the second experimental model were $586 \mathrm{HV}, 607 \mathrm{HV}, 249 \mathrm{HV}$. While the results of surface hardness value of the third experimental model were $313 \mathrm{HV}, 574 \mathrm{HV}, 677 \mathrm{HV}$. From the results of surface hardness of SUS304 specimen and observation of variable parameters could be concluded that the ratio between the flow rate of nitrogen and hydrogen gas into the vacuum chamber and gas pressure affected the value of the surface hardness. At the gas pressure of $60 \mathrm{~Pa}$ and the nitrogen gas flow rate of 180 ( $\mathrm{ml} / \mathrm{min}$ ) obtained the highest surface hardness value of $677 \mathrm{HV}$.
\end{abstract}

Keywords: RF Plasma Nitriding, Surface hardness, SUS304

\section{PENDAHULUAN}

Plasma nitriding adalah proses nitriding melalui diffusi ion gas nitrogen pada bahan logam. Reaksi pada plasma nitriding tidak melalui temperatur tinggi akan tetapi melalui gas nitrogen yang terionisasi. Ion nitrogen terjadi ketika gas nitrogen murni dialirkan ke dalam vacuum chamber dan diberikan medan listrik pada gas tersebut. Medan listrik yang kuat akan menghasilkan molekul-molekul gas yang terionisasi yang disebut sebagai plasma. Plasma dapat didefinisikan sebagai gas panas yang terionisasi dan memiliki jumlah ion bermuatan positif dan elektron bermuatan negatif yang sama. Plasma nitriding seringkali digunakan sebagai proses perlakuan pada permukaan (surface treatment) pada bahan logam untuk meningkatkan kekerasan permukaan (surface hardness), ketahanan aus (wear resistance) dan ketahanan korosi (corrosion resistance).

Kekerasan permukaan atau kekerasan mikro (micro hardness) pada spesimen uji stainless steel AISI316 hasil plasma nitriding selama 3 jam pada temperatur $400^{\circ} \mathrm{C}$ dengan persentase hidrogen dalam campuran gas telah diteliti. Dalam penelitian tersebut besar laju alir gas nitrogen (3.3-13.3) $\mathrm{mmol}^{-\mathrm{s}^{-1}}$ dan laju alir gas hidrogen $(0-73.5) \mathrm{mmol} . \mathrm{s}^{-1}$. Tekanan parsial gas hidrogen (0-450) $\mathrm{mPa}$, sedangkan tekanan vakum adalah (5-100) mPa. Tekanan parsial gas nitrogen yang digunakan pada seluruh perlakuan adalah $150 \mathrm{mPa}$ [1].

Penelitian untuk menjelaskan aksi hidrogen pada plasma nitriding telah dilakukan pada sampel austenitic stainless steel AISI316 yang mengalami RF Plasma Nitriding menggunakan tekanan rendah dan variasi campuran antara nitrogen dan hidrogen. Penambahan debit hidrogen murni pada debit nitrogen murni meningkatkan ketebalan dan konsentrasi nitrogen pada lapisan yang mengalami plasma nitriding dibandingkan dengan sampel yang tidak mendapat penambahan hidrogen. Komposisi campuran $\mathrm{N}-25 \% \mathrm{H}$ menghasilkan ketebalan lapisan dan kandungan nitrogen yang lebih besar. Peningkatan ketebalan lapisan nitriding disebabkan oleh keberadaan jumlah ion hidrogen pada proses plasma nitriding di bawah permukaan spesimen [2].

Gambar 1 menunjukkan instalasi RF-plasma nitriding yang digunakan pada penelitian. RF plasma generator yang digunakan pada penelitian adalah jenis capasitive discharge. Capasitive discharge adalah plasma non termal yang dihasilkan melalui penggunaan daya Radio Frequency (RF Power) misalnya, $13.56 \mathrm{MHz}$ untuk satu elektroda yang mendapatkan daya [3]. 


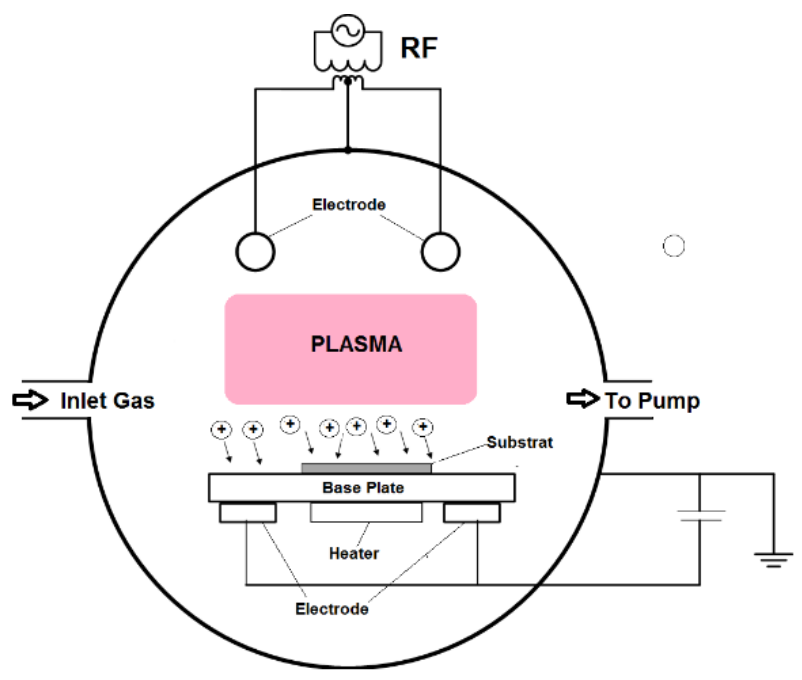

Gambar 1. Instalasi RF-Plasma Generator

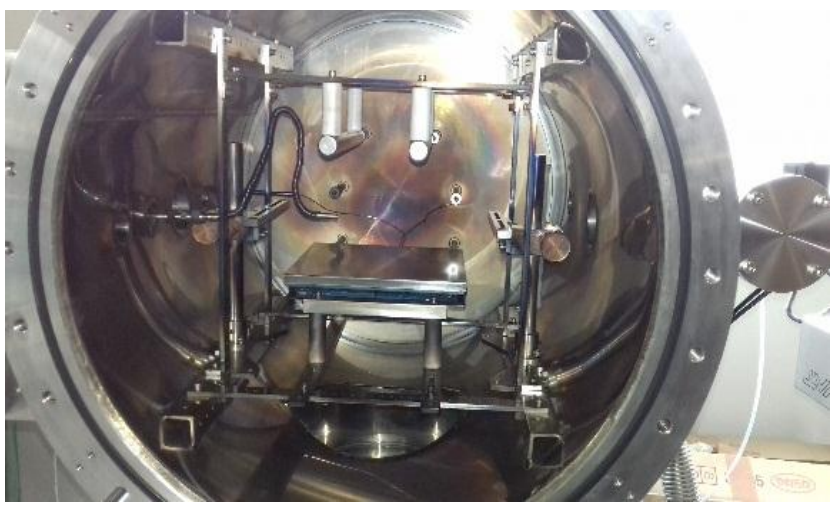

Gambar 2. Bagian dalam instalasi vacuum chamber untuk proses RF plasma nitriding.

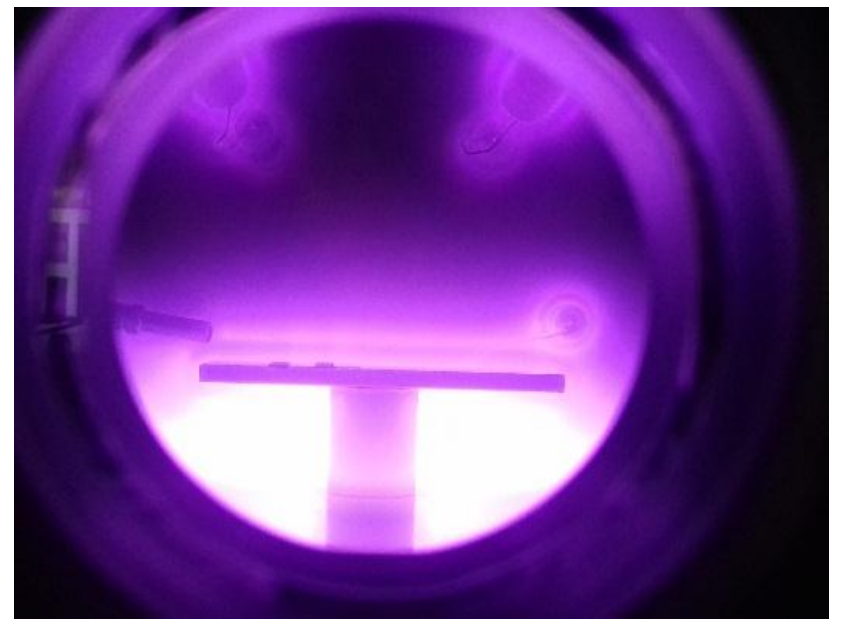

Gambar 3. Proses glow discharge pada RF plasma nitriding.

Dalam penelitian frequency yang digunakan pada Instalasi RF plasma nitriding adalah $2.0 \mathrm{MHz}$. Instalasi RF plasma generator tersebut merupakan instalasi plasma tanpa Jammer. Bagian dalam instalasi chamber untuk RF plasma nitriding yang digunakan pada penelitian ditunjukkan pada gambar 2 dibawah ini. Gambar 3 menunjukkan proses RF plasma nitriding yang sedang berlangsung. Warna keunguan pada gambar 3 tersebut menunjukkan plasma yang terjadi. Fenomena tersebut disebut sebagai glow discharge.

Glow discharge adalah plasma yang dihasilkan oleh aliran arus listrik melalui gas dalam ruang vakum atau bertekanan rendah. Plasma dihasilkan menggunakan tegangan listrik antara dua elektroda logam dalam ruang (tabung) hampa berisi gas. Ketika tegangan listrik melebihi nilai tertentu yang disebut sebagai tegangan penyalaan (striking voltage), maka gas terionisasi menjadi plasma dan mulai menghantarkan listrik yang menyebabkan gas bersinar dengan cahaya berwarna. Warna cahaya yang dihasilkan tergantung pada gas yang digunakan.

\section{METODOLOGI PENELITIAN}

Penelitian yang telah dilakukan bersifat eksperimental. Penelitian ini dibagi menjadi tiga model eksperimen. Tiap model eksperimen memiliki variable parameters dan constant parameters. Pada model eksperimen pertama, parameter yang divariasikan adalah waktu plasma nitriding, yaitu, 1 jam, 2 jam, 4 jam dan 8 jam. Parameter konstan pada model eksperimen pertama adalah, RF-Voltage $=250$ Volt, DC-bias voltage $=500$ Volt, $\mathrm{N}_{2}=100(\mathrm{ml} / \mathrm{menit}) ; \mathrm{H}_{2}=$ 20 (ml/menit) dan tekanan gas $(P)=70 \mathrm{~Pa}$. Temperatur Heater $(\mathrm{T})=420^{\circ} \mathrm{C}$. Gambar 4 menunjukkan konfigurasi yang digunakan pada model eksperimen pertama.
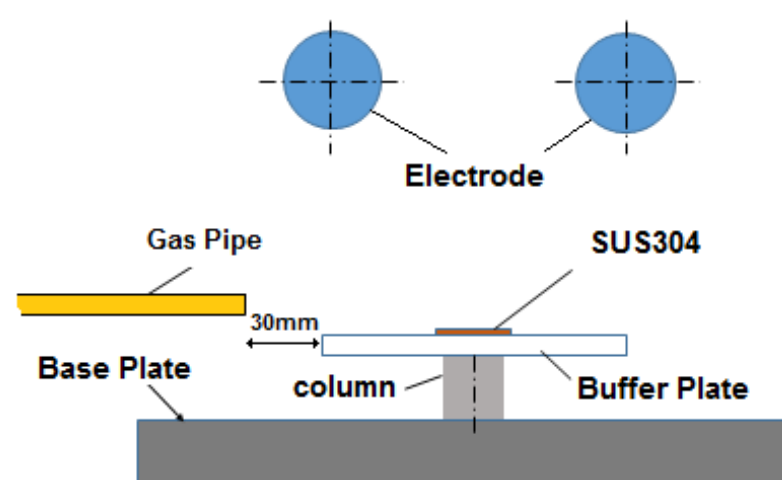

Gambar 4. Konfigurasi RF-plasma nitriding pada model eksperimen pertama

Model eksperimen kedua menggunakan tiga variasi parameter tekanan gas Nitrogen sebesar 50 $\mathrm{Pa}, 60 \mathrm{~Pa}$ dan $70 \mathrm{~Pa}$. Parameter yang dijaga konstan pada model eksperimen kedua adalah; waktu plasma nitriding $(\mathrm{t})=8$ jam, RF-Power Voltage $=250$ Volt,Temperatur Heater $(\mathrm{T})=420^{\circ} \mathrm{C}, \quad \mathrm{N}_{2}=$ 140 (ml/menit), laju alir gas, $\mathrm{m} \mathrm{H}_{2}=20$ (ml/menit). Model eksperimen pertama dan kedua memiliki konfigurasi yang sama.

Pada model eksperimen ketiga digunakan tiga variasi laju aliran gas Nitrogen kedalam vacuum chamber. Variasi laju aliran gas Nitrogen yang digunakan adalah 140 (ml/menit), 160 (ml/menit), 180 (ml/menit). Parameter yang dijaga konstan pada model eksperimen ketiga adalah waktu plasma 
nitriding $(\mathrm{t})=4 \mathrm{Jam}, \mathrm{RF}-\mathrm{Power}$ Voltage $=250$ Volt, temperatur heater $(\mathrm{T})=420^{\circ} \mathrm{C}$, laju alir gas $\mathrm{H}_{2}=$ $20(\mathrm{ml} /$ menit $)$, DC-Bias Voltage $=500$ Volt, Tekanan gas yang masuk ke dalam vacuum chamber $(P)=60$ $\mathrm{Pa}$. Konfigurasi pada model eksperimen ketiga berbeda dengan konfigurasi pada model eksperimen pertama dan kedua. Gambar 5 menjelaskan konfigurasi yang digunakan pada model eksperimen ketiga.

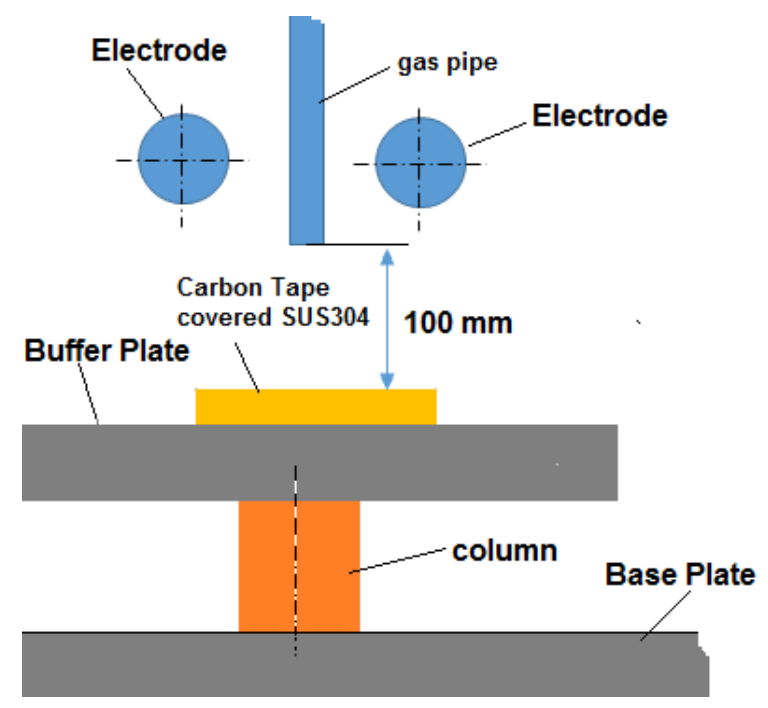

Gambar 5. Konfigurasi RF-plasma nitriding pada model eksperimen ketiga

Gambar 6 berikut ini menunjukkan kondisi sebenarnya untuk konfigurasi model eksperimen ketiga sebelum dilakukan proses RF plasma nitriding.

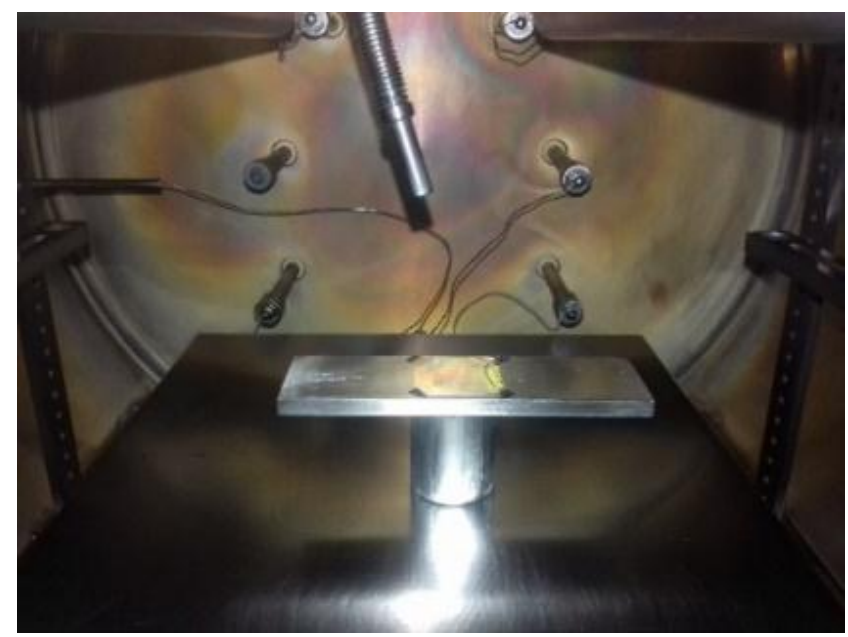

Gambar 6. Kondisi sebenarnya model eksperimen ketiga pada vacuum chamber sebelum RF plasma nitriding.

Pengukuran kekerasan permukaan dilakukan terhadap spesimen hasil RF Plasma nitriding untuk tiap model eksperimen. Metode pengukuran kekerasan permukaan yang dikunakan adalah Micro Vickers Hardness Test. Beban yang digunakan pada pengukuran kekerasan permukaan tersebut adalah 25 gf.

Spesimen yang digunakan dalam penelitian adalah stainless steel sheet SUS304. Gambar 7 menunjukkan dimensi spesimen yang digunakan pada penelitian.

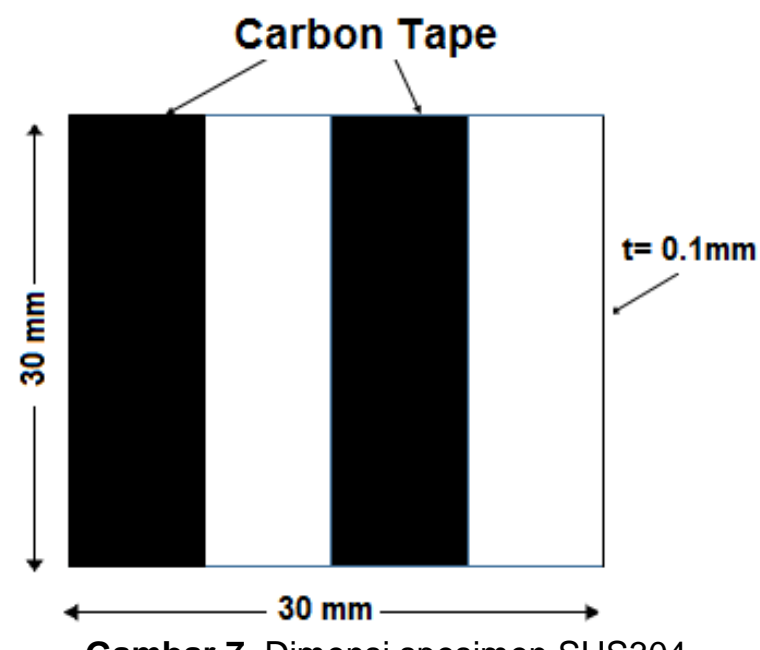

Gambar 7. Dimensi spesimen SUS304

\section{HASIL DAN PEMBAHASAN}

Hasil pengukuran kekerasan permukaan pada model eksperimen pertama ditampilkan pada grafik pada Gambar 8 berikut. Grafik tersebut menjelaskan bahwa kekerasan permukaan rata-rata tertinggi terjadi pada pada waktu plasma nitriding 4 jam. Grafik tersebut juga menjelaskan bahwa peningkatan kekerasan permukaan tidak begitu besar jika dibandingkan dengan kekerasan permukaan bagian yang tidak mengalami plasma nitriding.

Surface Hardness Average of SUS304 Specimen VS Time of RF Plasma Nitriding

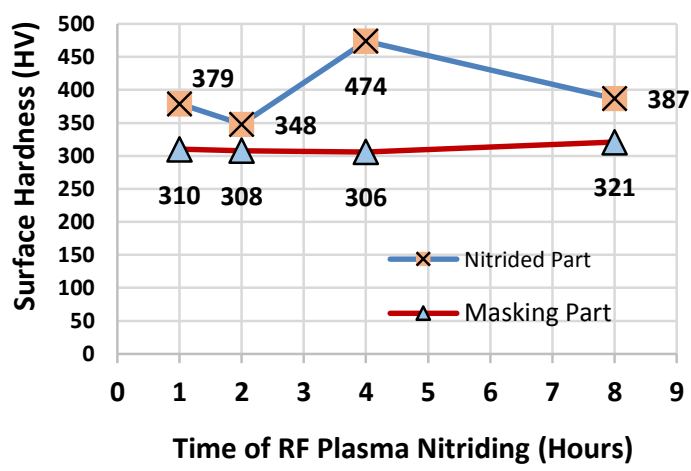

Gambar 8. Kekerasan permukaan rata-rata untuk tiap waktu plasma nitriding pada SUS304.

Hasil kekerasan permukaan rata-rata dari model eksperimen kedua ditunjukkan pada Gambar 9. Kekerasan permukaan rata-rata tertinggi dari spesimen SUS304 setelah RF-Plasma Nitriding terjadi pada gas pressure sebesar $60 \mathrm{~Pa}$. Pada grafik ditunjukkan bahwa pada gas pressure $70 \mathrm{~Pa}$, tidak terjadi peningkatan kekerasan permukaan. 


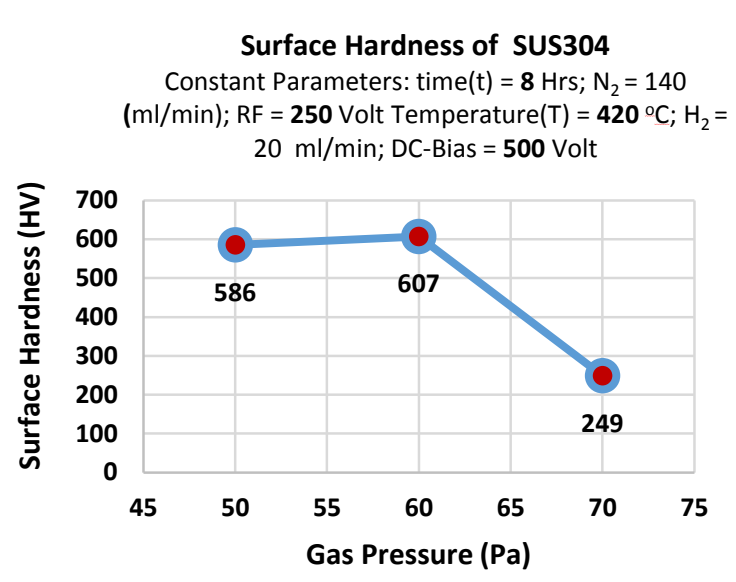

Gambar 9. Kekerasan permukaan rata-rata spesimen SUS304 terhadap variasi gas pressure pada RF plasma nitriding.

Hasil pengukuran kekerasan permukaan pada model eksperimen ketiga ditampilkan pada grafik pada Gambar 10 berikut. Rasio laju alir Hidrogen-Nitrogen sebesar (20ml/min:140ml/min) diperoleh nilai kekerasan permukaan rata-rata spesimen sebesar $313 \mathrm{HV}$. Pada rasio laju alir Hidrogen-Nitrogen (20 $\mathrm{ml} / \mathrm{min}: 160 \mathrm{ml} / \mathrm{min}$ ) didapatkan nilai kekerasan permukaan rata-rata spesimen sebesar 574 HV. Grafik pada gambar 10 juga menunjukkan bahwa nilai kekerasan permukaan tertinggi terjadi pada laju alir nitrogen murni (nitrogen flow rate) sebesar $180(\mathrm{ml} / \mathrm{min})$ untuk laju alir Hidrogen konstan sebesar $20 \mathrm{ml} / \mathrm{min}$.

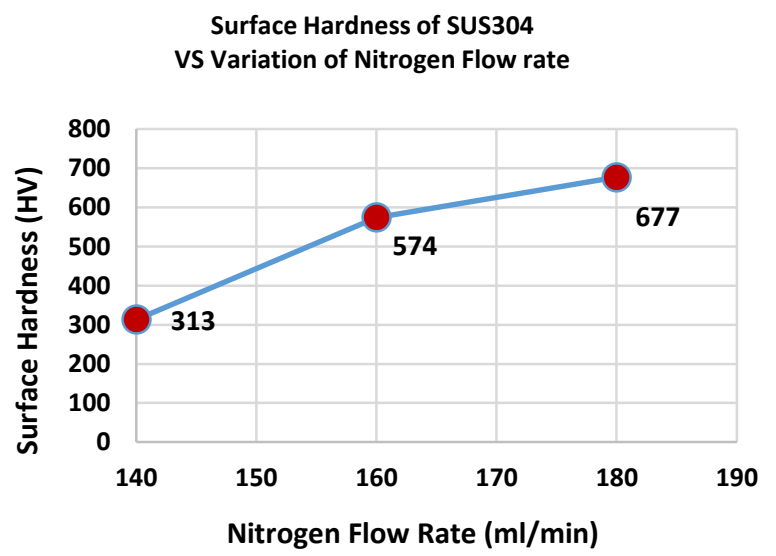

Gambar 10. Kekerasan permukaan rata-rata spesimen SUS304 untuk variasi Nitrogen flow rate pada RF plasma nitriding.

\section{KESIMPULAN}

Dari hasil pengujian kekerasan permukaan pada spesimen SUS304 dan pengamatan terhadap variasi parameter disimpulkan bahwa

1. Model eksperimen ketiga dari RF plasma nitriding memiliki nilai micro hardness yang lebih konsisten dari pada model eksperimen pertama dan kedua.

2. Perbandingan antara laju alir gas nitrogen dan laju alir gas hidrogen ke dalam vacuum chamber berpengaruh terhadap nilai kekerasan permukaan spesimen SUS304.

3. Besar tekanan campuran gas (gas mixture) juga berpengaruh terhadap nilai kekerasan permukaan spesimen SUS304.

4. Pada tekanan gas sebesar $60 \mathrm{~Pa}$ dan laju alir gas Nitrogen sebesar $180(\mathrm{ml} / \mathrm{min})$ dan laju alir hidrogen yang konstan sebesar $20(\mathrm{ml} / \mathrm{min})$ diperoleh nilai kekerasan permukaan (micro hardness) tertinggi sebesar $677 \mathrm{HV}$.

\section{DAFTAR PUSTAKA}

[1] S. Kumar,M.J. Baldwin, M.P. Fewell, S.C. Haydon, K.T. Short, G.A. Collinsb, J. Tendys, 2000, Surface and Coatings Technology 123 (2000) 29-35, Elsevier.

[2] J.M. Priest, M.J. Baldwin, M.P. Fewell, 2001, Surface and Coatings Technology 145(2001) 152163, Elsevier.

[3] M.A. Lieberman, A.J. Lichtenberg, Principles of Plasma Discharge and Material Processing, 1618(2005), John Wiley \& Sons. 